\title{
Information Management and Socio-economic Factors of Type 2 Diabetes Patients: A Case Study of Kigali City; Republic of Rwanda
}

\section{Nasiru Sani' ${ }^{*}$, Adamu Abdullahi Muhammed², Lawal Shuaibu ${ }^{3}$, Ahmed Ankuwa Abubakar ${ }^{4}$ and Habibu Sada El-Rufa' ${ }^{5}$}

${ }^{1}$ College of Medicine and Health Sciences, Federal University Dutse, Jigawa State, Nigeria

${ }^{2} J . D$ Amin Library, Federal University Dutse, Jigawa State, Nigeria

${ }^{3}$ Shehu Idris College of Health Sciences and Technology, Makarfi, Kaduna State,

Nigeria

${ }^{4}$ Department of Nursing, Kaduna State College of Nursing and Midwifery, Kaduna State, Nigeria

${ }^{5}$ Department of Health Information Management, Shehu Idris College of Health

Sciences and Technology, Makarfi Kaduna, Nigeria

*Corresponding Author: Nasiru Sani, College of Medicine and Health Sciences, Federal University Dutse, Jigawa State, Nigeria.

\section{Received: October 14, 2021}

Published: December 06, 2021

(C) All rights are reserved by Nasiru Sani., et al.

\begin{abstract}
The study investigates information management and Socio-Economic Factors of Type 2 Diabetes Patients in Kigali City, Republic of Rwanda. The aim the study is to determine socio-economic factors associated with types 2 diabetes complications; and identify diabetes complications, and to establish the relationship between socio-economic factors and these complications. The adopted survey research design using cross-sectional. The target population comprises all the registered diabetes patients registered at Rwanda Diabetes Association which are seven hundred and forty eight (748) diabetic patients. Purposive sampling technique was used to determine the sample size of the study. The researcher adopted a structured questionnaire as instrument for data collection. The data was analysed using SPSS version 21.0. The study found that more than half $52.7 \%$ of the respondents had completed secondary school, less than half $48.2 \%$ had regular employment, $60.2 \%$ had less than 100,000 Frws, and $82.7 \%$ used health insurance and manual insurance. The study also revealed that most of the respondents have low-income. The study recommended that There should be active health policies on diabetes disease in Rwanda, there should be empowerment programmes that will improve the standard of living of the diabetes patients and lastly the recommended that there should be effective health information management to reduce the prevalence of diabetic complications in Rwanda.
\end{abstract}

Keywords: Information Management; Socio-économique; Type 2 Diabetes; Kigali; Rwanda

\section{Introduction}

Effective information systems support the provision of effective healthcare services. Economic well-being of people is one of the factors for good healthcare status. People need money to practice good health lie style and pay for their medical bills. Many people actively seek health-related information. However, some patients receive information involuntarily or by chance during their daily activities from different information sources such as watching a $\mathrm{TV}$, radio, newspaper etc.
Diabetes is non-communicable disease is has become one of the global health issue and Africa inclusive. According to [4] there are three basic types of diabetes:

- Types 1 which emanates from lack of insulin owing of pancreatic cells and mostly impacts young people and adults.

- $\quad$ Type 2 Diabetes (T2D), about $85 \%-95 \%$ of all cases, was considered by insulin confrontation as when the body no longer utilizes insulin adequately. 
- $\quad$ Type 3 this type refers to gestational diabetes that appears only during pregnancies.

The global prevalence Diabetes is estimated to 380 million with the figures projected to rise to 438 million by the year 2030 if no interventions are put in place [5]. An estimated 4.6 million die from diabetes globally each year [4]. Furthermore, four out of five cases of diabetes are from less and developed countries, most of them being in Sub-Saharan Africa. Diabetes is one of the most common health issues in Africa and the estimated number of cases in 2015 stood at 12.1 million of about (3.2\%) in adult population with only 15\% diagnosed (IDF, 2015). Another study by WHO (2016), revealed that African counties are predicted to have more relative increase of about (27\%) of diabetes patients. The Ministry of Health of Rwanda (2016), reported that about (43\%) of hospital admissions in Kigali were due to NCDs where diabetes contributed about (27.3\%) of the total bed occupancy. According to Rwanda Diabetes Association (RDA), more than 194,300 people in Rwanda today are suffering from diabetes and their number is estimated to be increased by 2030 if no preventive measures are put in place [7].

Unfortunately, when poorly managed, some long-term complications occur among patients with Type two. There are Long-term complications due to diabetes may be alienated into vascular and non-vascular complications. Studies show that there is lack of treatment for diabetes traditional treatment approaches had normally put together clinical models that copy these conditions or reduce warning signals with behavior change such as ameliorating diet conditions, more physical activities and carefully follow up on how patients are taking medicine regimes (Centers for Disease Control and Prevention [4]. This study thus endeavors to explore whether an approach addressing socio-economic determinants that plays a vital role in diabetes health care in Rwanda, with a particular focus on preventive measure.

\section{Problem statement}

Management of diseases in low-income countries is difficult because financial implication is always a challenging factor for management of health status. The economic well-being of people is highly significant is maintaining good health. Most of the lowincome nations are in African continent. This is why some diseases such as diabetes is still an issue. As such, people need to have access to health information in order to be informed on how to pre- vent themselves and manage their health conditions effectively. Moreover, the growing medical issue worth taking serious diabetes and its associated complications [11]. In 2014\%, 8.5\% of people aged 18 and more had diabetes. In 2016 diabetes become the direct root of 1.6 million deaths and in 2012 high blood glucose was the root of another 2.2 million deaths. The prevalence of diabetes worldwide is $3 \%$ among 170 million infected [12]. Another study shows that the prevalence of diabetes in Southern Rwanda was $13.1 \%$ and $3.9 \%$ outside of Rwanda [13]. Recently, Diabetes Atlas shows that the rate of diabetes in Rwanda is estimated to be about $3.6 \%$ of the population with 1918 diabetes associated deaths each year. In Rwanda, $4.4 \%$ of diabetic patients had stroke, vascular complications such as nephropathy, coronary artery disease (CAD) and erectile dysfunction. Types 2 diabetes is called the killer due to hyperglycemia, leading to pathologic and functional adjustment in target tissues without clinical symptoms. It is against this background that the study aims to Information Management and Socio-Economic Factors of Type 2 Diabetes Patients in Kigali City of Rwanda.

\section{Research objectives}

- $\quad$ To determine information needs of diabetes patients in Kigali City, Rwanda;

- $\quad$ To determine the socio-economic factors of Type 2 diabetes patients in Kigali City Rwanda;

- To determine the relationship between socioeconomic factors and Type 2 diabetes complications among diabetes patients in Kigali City Rwanda.

\section{Literature Review}

The review is done under the following:

Socio-economic factors associated with type 2 diabetes complications

Socio-economic factors associated with Type 2 Diabetes complications include the following: lack of enough money, inaccessibility to necessary assets for managing patents' conditions, and decreased personal production at working place. Financial resources play a role in the management of Type 2 Diabetes complications. However, occupations or incomes of people will determine their well-being as well as management of their health conditions [22]. In 2014 , about $8.5 \%$ of people aged 18 years old and more had diabetes while in 2016 diabetes become the cause of death of 1.6 mil- 
lion. However, in 2012 high blood glucose was the cause of death of another 2.2 million people, the prevalence of diabetes worldwide is $3 \%$ among 170 million infected [23]. The prevalence of diabetes worldwide is a global disease.

Diabetes prevalence have been active for the past two decades and the estimate was around 30 million patients and in 2010 it raised to 285 million people and raised to 438 million by 2030 . The literature shows that prevalence of Type 1 diabetes and Type 2 diabetes is generally increasing worldwide. According to Engum (2005), type 2 diabetes prevalence is rapidly is increasing than the type 1 diabetes. The prevalence of diabetes is also high in other continent like Asia, in Philippines it was reported to be $2-3 \%, 2$ in Malaysia 3\%, in Japan 1.2\%. But, the case is different in Europe with low prevalence of diabetes countries like United Kingdom, and Scandinavian countries with $0.01 \%-0.1 \%$, meaning the average of diabetes is less than $1 \%$. The higher prevalence rate was found in Africa specifically in Egypt with 15\%-20\% rate. The prevalence of diabetes in Eastern Africa is estimated to be $3 \%$, in West Africa is about 4.14\%, Central Africa 7.82\%, Southern Africa 0.72\%, (Sub-Saharan Africa, 200-2013). The lower prevalence of diabetes is Zimbabwe (1-3\%), Kenya (1.7\%), Sudan (2.8\%), Gabon (9.2\%), and CAR (2.4\%), Mercy, 2013). A study conducted among 324 patients attending Rwanda Military Hospital found the rate of diabetes is about $28.4 \%$, for 55 old patients while $28.4 \%$ in younger patients, aged (18-35 years). The diabetes is highly common in adults patients, the risk factors of infection of diabetes prevalence in general population is not clear (Umumararungu., et al. 2017).

Common diabetic complications among type diabetes patients

Complications diabetes disease may be divided into: microvascular and macro vacular. Microvascular complications affect the small blood vessles while that of macrovascular affect white blood vessels [25]. The severe microvascular and macro vascular complications happen due to diabetes mellitus which is the major implications (Nisar, 2015). It was reported that diabetics with both microvascular and macrovascular vascular complications spend a total treatment cost of up to two-and-half times more compared to those without complications. The substantial cost of managing diabetes is aggravated by microvascular and macrovascular complications which are the major cause of healthcare costs [26]. In African diabetes complications is high and costly. (Morsanutto., et al. 2006). These include emotional distress such as stroke, neural damage, foot ulcer leading to amputation, heart attack, kidney damage and blindness etc. [27].

Apart from these complications, diabetes is often associated with certain comorbidities. For instance, patients with diabetes nephropathy have high risk for excess cardiovascular morbidity. In Tanzania, $4.4 \%$ of people living type 2 diabetes had been diagnosed with stroke, Type 2 diabetes was seen as hyerglycemia which may be available in a long time before diagnosis, leading to pathologic and functional adjustments in target parts without clinical [22]. The macrovascular complications for instance heart attack, strokes, deficiency in blood stream to legs. Furthermore, apart from these complications, diabetes is often associated with certain comorbidities.

Relationship between Socioeconomic factors and type 2 diabetes complications

Review reveals shows that of the relationship between the prevalence of diabetes and its complications which depends on the impact of health factors. A study carried out in America shows that the diabetes related hypertension demonstrated as statistically significant with diabetes in multivariate inferential analysis. (Safraj, 2012). Regional studies in Africa demonstrated how the prevalence of diabetes is associated with several factors. Another study conducted in Nigeria revealed that factors influencing diabetes are marital status, employment, location, availability of health facilities and other complication were demonstrated as factors associated with diabetes. (Oladeinde., et al. 2012). Regional studies have been conducted in Kenya, Ethiopia, Uganda and Tanzania evidenced the relationship between these factors and diabetes incidence of low birth weight is highly linked to the accessibility to medicaments [26].

The biological factors at birth affect the likelihood of developing diabetes later on. It is estimated that around $40 \%$ of predispositions to diabetes are attributed to genetic causes. These are preventable as the individual will be influenced by factors associated to birth such as the parent's SEP, the age and stage of the onset, the country or region where the community lives and the ethnicity of the individual (WEF, 2015). All these factors determine the onset of diabetes and accompany the individual until his/her death. For example, the quality of life depends on the ability to have a healthy diet, physical activity and maintaining good control of blood glucose levels [24]. 
Conceptual framework

Oren's self-care theory (1995)

The study is conceptualized on the Oren's Self-Care Theory. SelfCare has been the strength to conceptualize this this study because self-care action is one of the habit of diabetes patients. Self-Care Agency comprises of self-care and estimative actions of self-care. A conceptual framework is a systematic scheme that tried to establish the relationship between independent and dependent variables in a particular study. Below the diagram of the conceptual model of this study.

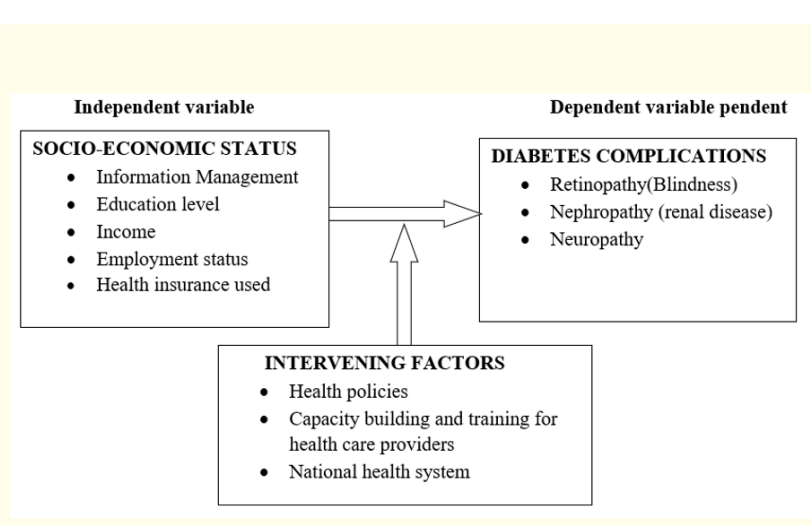

Figure 1: Conceptual Framework.

\section{Materials and Methods}

This study is quantitative in nature using cross-sectional design. It was conducted on a baseline in a cohort study. The target population comprises all the registered diabetes patients registered at Rwanda Diabetes Association which are seven hundred and forty eight (750) diabetic patients. Purposive sampling technique was used to determine the sample size of the study. The study adopted a structured questionnaire as instrument for data collection. This instrument was used in collecting both quantitative and qualitative data. The questionnaires were distributed to the respondents by the researchers with the help of research assistant for follow up. The sample sample size was determine using Krejcie and Morgan Table (1970) which states that a total population of 750, the sample size will be 256. The data was analysed using SPSS version 20.0 for the evaluation of statistical significance helped in analyzing statistical information in order to establish the information management and socio-economic factors in health care for diabetes condition management.

\section{Results and Analysis}

Socio-demographic characteristics of respondents

The study was carried out to Socio-demographic characteristics of respondents who are selected from diabetes patients attending the Rwanda Diabetes Association Clinic in the City of Kigali.

\begin{tabular}{|l|c|c|c|}
\hline \multirow{2}{*}{ Variables } & Values & Frequency & $\begin{array}{c}\text { Percentage } \\
\text { G\%) }\end{array}$ \\
\hline \multirow{2}{*}{ Total } & Male & 83 & $32.4 \%$ \\
\cline { 2 - 4 } Age & Female & 173 & $67.6 \%$ \\
\hline \multirow{2}{*}{ Total } & $18-34$ & 147 & $57.4 \%$ \\
\hline \multirow{2}{*}{ Marital Status } & $>35$ years & 109 & $42.6 \%$ \\
\hline \multirow{2}{*}{ Total } & & 256 & $100 \%$ \\
\hline \multirow{2}{*}{ Duration of Diabetes } & Married & 233 & $91.0 \%$ \\
\cline { 2 - 4 } & Not Married & 23 & $9.0 \%$ \\
\hline \multirow{2}{*}{ Total } & & 256 & $100 \%$ \\
\hline
\end{tabular}

Table 1: Socio-Demographic Characteristics of Respondents.

Source: Primary Data (2021).

The table shows that $83(32.4 \%)$ are male while $173(67.6 \%)$ are female. The table also reveals that 147 (57.4\%) of the respondents are under the age of 18-34 years, 109 (42.6\%) of the respondents are above 35 years of age. The study further indicates that $233(91.0 \%)$ of the respondents are married and $23(9.0 \%)$ are single. The study shows that $133(52.7 \%)$ of the respondents have been suffering from diabetes for more 10 years, while 88 (33.8\%) of the respondents have been suffering from diabetes for 10-20 years only 35 (13.5\%) of the respondents have been suffering from diabetes for more than 20 years. This implies that majority of the diabetes patients in Kigali are female and they are 18-34 years, they are also married couples.

Table 2 shows the information sources the respondents can be categorized into interpersonal relations, traditional media and news media. As can be seen in table 3 , the interpersonal relations 


\begin{tabular}{|l|c|c|c|c|c|}
\hline $\begin{array}{l}\text { Information } \\
\text { Source }\end{array}$ & Average & $\begin{array}{l}\text { Standard } \\
\text { Deviation }\end{array}$ & Minimum & Maximum & P-Value \\
\hline $\begin{array}{l}\text { Interpersonal } \\
\text { Relations }\end{array}$ & 24.12 & 9.65 & 3.13 & 63.89 & \\
\hline $\begin{array}{l}\text { Traditional } \\
\text { Media }\end{array}$ & 19.14 & 12.83 & 0.00 & 67.50 & $<0.001$ \\
\hline New Media & 8.02 & 18.76 & 0.00 & 100.00 & \\
\hline
\end{tabular}

Table 2: Information Sources of the Respondents

have an average of (24.12), whereas the new media had an average of (8.02). ANOVA test with repeated observations showed that there is a statistically significant difference between the sources of information $(\mathrm{P}<0.001)$. This means that the main information sources of the respondents is interpersonal relations.

\begin{tabular}{|l|c|c|c|c|c|}
\hline Option & Average & $\begin{array}{l}\text { Standard } \\
\text { Deviation }\end{array}$ & Minimum & Maximum & P-Value \\
\hline $\begin{array}{l}\text { Active } \\
\text { Information } \\
\text { seeking }\end{array}$ & 39.20 & 12.03 & 16.67 & 88.89 & $<0.001$ \\
\hline $\begin{array}{l}\text { Passive } \\
\text { information } \\
\text { receipt }\end{array}$ & 41.68 & 13.37 & 16.67 & 91.67 & \\
\hline
\end{tabular}

Table 3: Information Seeking Behaviour of Diabetes Patients.

Table 3 above compares the active information seeking with passive information receipt among diabetic patients. The paired $t$ test showed that differences between passive information receipt (41.68) and active information seeking (39.20) are considered statistically significant $(39.20, \mathrm{P}<0.001)$. The analysis of the data identified the information-seeking behavior of diabetic patients in Kigali and the most valuable information sources used by them. By identifying the search patterns of diabetic patients, it is possible to devise a method for effective sharing of information through sources such as practitioners, television, family members, news, other health care providers, radio, and nurses.

\begin{tabular}{|l|c|c|c|}
\hline \multirow{2}{*}{ Items } & & Frequency & Percentage \\
\hline \multirow{2}{*}{$\begin{array}{l}\text { Education } \\
\text { level }\end{array}$} & Illiterate and Primary & 66 & $25.7 \%$ \\
\cline { 2 - 4 } & Secondary Level & 138 & $53.9 \%$ \\
\cline { 2 - 4 } & University level & 52 & $20.4 \%$ \\
\hline Total & & 256 & $100 \%$ \\
\hline
\end{tabular}

\begin{tabular}{|l|c|c|c|}
\hline \multirow{2}{*}{ Employment } & No employment & 72 & $28.2 \%$ \\
\cline { 2 - 4 } & Irregular employment & 63 & $24.6 \%$ \\
\cline { 2 - 4 } & Regular employment & 121 & $47.2 \%$ \\
\hline \multirow{2}{*}{ Total } & & 256 & $100 \%$ \\
\hline \multirow{2}{*}{\begin{tabular}{l} 
Income level \\
\cline { 2 - 4 }
\end{tabular}} & <100,000Frws & 37 & $14.6 \%$ \\
\hline Total & $>200.001$ Frws & 65 & $25.3 \%$ \\
\hline $\begin{array}{l}\text { Type of } \\
\text { health } \\
\text { insurance }\end{array}$ & Mutal Health Insurance & 45 & $17.6 \%$ \\
\cline { 2 - 4 } & Others & 211 & $82.4 \%$ \\
\hline Total & & 256 & $100 \%$ \\
\hline
\end{tabular}

Table 4: Socio-Economic Factors of Type 2 Diabetes Patients. Source: Primary data (2021).

Table 4 reveals that more than half 138 (53.9\%) of the respondents have secondary school education, 66 (25.7\%) of the respondents are illiterate or have only primary school education while only $52(20.4 \%)$ of the respondents have attended university. The study shows that 121 (47.2\%) of the respondents are regular employed, $72(28.2 \%)$ of the respondents are not employed. The study indicates majority 154 (60.1\%) of the respondents have an average income of 100,001Frws-200,000Frws, 65 (25.3\%) of the respondents have more than 200.001Frws, 37 (14.6\%) of the respondents have less than 100,000Frws. This implies that most the diabetes patients in Kigali City have average educational level and have average income.

\section{Discussion of Findings}

Analysis of the data showed that the information sources used by diabetic patients in the city of Kigali included interpersonal interactions with people such as practitioners, nurses, other health care providers, and charity or support organizations for diabetic patients, family members, friends, co-workers, other diabetic patients and medical librarians. These findings is similar to the results of Andreassen [9] who reported that practitioners were the most popular information source among patients. Also studies by [9] and Longo., et al. showed that patients consider television and interpersonal relations to be the best source for medical information, which are in line with the findings of this study. The results of this study are also in confirmation with the results reported by 
Evans., et al. reported that Internet was used less than other information sources by the patients. The results of this study also contrasted with that of Wang., et al. who reported newspaper and magazines as the most commonly used information sources among adult Chinese citizens. Furthermore, the results also contrasted with the study of Shaw who named Internet to be among the most commonly used information sources. The discrepancies in findings could be due to cultural difference, lack of widespread Internet use in Iran, digital gap between Iran and developed country and the type of a disease investigated. However, most of the diabetic patients investigated in this study were elderly people with limited internet access.

Moreover, the study examine the relationship between socioeconomic factors and diabetic complications of rethnopathy, neuropathy and nephropathy among diabetes patients, the results indicated that among patients with diabetes, the odds of having retinopathy, neuropathy and nephropathy were higher among those with lower SES, such as those who had primary and secondary education level, those with a lower or middle income level, those in the first and second category of social classification and those with irregular or unemployment.

The present results accord with those of findings on relation between SES and diabetic complication prevalence. Furthermore, they accord with studies carried out in Italy and France using the poverty indexes of those countries, which indicated that poorer individuals tended to have a greater prevalence of retinopathy and nephropathy (Fano., et al. 2013) Similarly a study UK reported a higher prevalence of retinopathy among those living in deprived areas (Kondo, 2012), as did a study in German (Reisig, 2017). In Contrast, another study in the UK on patients visiting general practitioners found no relationship between the local poverty index and neuropathy, retinopathy or nephropathy (Gary-Webb, 2013).

In Rwanda, only four previous studies have discussed the relation between SES with T2DM. A research focusing on public servants found that prevalence of diabetes was higher among those with lower education and low level work. (Mukeshimana, 2010). While a study targeting the general population observed at low income individuals tended to have a higher diabetes treatment rate. As to the relationship of SES with diabetes complications in Rwanda, there has been no examination to date this makes our first. As such further investigation of this relationship in Rwanda must be performed.

\section{Conclusion}

The study concluded that there are more female patients than the male patients and they are at the age of 18-34 years, and most of them are married, most of the patients suffer from diabetes disease for more 10 years. The study concluded that the information source of the respondents is mainly interpersonal relations. The study further concluded that information seeking behavior of the diabetes patients in Kigali City is active information seeking. The study concluded that the patients have secondary school education, only few of them obtained university education. The study also concluded that the patients' income is average.

\section{Recommendations}

Based on the findings of the study and conclusions drawn, the following recommendations were made:

- $\quad$ Diabetes Patients should have searching strategy skills to access health information for management of their health conditions

- Good diet, physical exercises and education should be the core of patient treatment to help to control and stabilize their level of diabetes

- $\quad$ Rwanda government should provide more information sources such, bill board, TV set.

- $\quad$ More employmenst should be provided the patients so that they will be able to pay for their medical bills.

\section{Bibliography}

1. Association- Diabetes Care. "American Cost of Diabetes in the YS". American Diabetes Care Journal 36.4 (2013): 1.

2. Health WCoSDo. "A Conceptual Framework for Action on the Social Determinant of health". Geneva (2017).

3. World Health Organization WHO. "World Health Organization. Closing the Generation, Health Equity through Action on the Social Determinant of Health". Geneva (2008).

4. K A. "Influence of Socio- Economic Factors on Diabetes Care" (2011).

5. K A. "Pathologic Basic of Disease". $7^{\text {th }}$ ed, Sunders Company, USA (2014).

6. Stefan Bjork., et al. "Global Policy: Aspect of Diabetes in India". Health Policy 66.1 (2013): 61-72. 
7. RDA. "Diabetes in Rwanda against all Odds". Kigali City (2016).

8. Jack L J. "Understanding the Environmental Issues in Diabetes Self- Management Education Research: A Reexamination of 8 Studies in Community -Based Settings". An International Journal of Medicine 1.140 (2004).

9. Glazier R B. “A Systematic Review of Interventions to Improve Diabetes Care in Socially Disadvantaged Populations". Diabetes Care 29.7 (2006): 1675-1688.

10. J C M. "Making a Difference to Global Diabetes Voice" 54.3 (2009).

11. Beulens J W. "The Global Burden of Diabetes and Its Complications: An emerging Pandemic". European Journal of Cardiovascular Prevention and Rehabilitation 17.1 (2010).

12. World Health Organisation WHO. "Global Report on Diabetes" (2015).

13. R D. "The Social Determinants of the Incidence and Management of Type 2 Diabetes Mellitus are we prepared to Rethink Our Questions and Redirect our Research Activities". International Journal Health Care Quality Assurance 16.3 (2013): 1623.

14. Golden S. "Examining a Bisectional Association between Depressive Symptoms and Diabetes". Group Health Research Institute: Improving Chronic Illness Care (2012).

15. Ada A Care. "Economic Cost of Diabetes in the U.S in 2012". Diabetes Care Journal 36.4 (2013): 1033-1046.

16. World Health Organisation WHO. World Health Organisation Report (2016).

17. Slater J. Socio- Demographic and Graphic Analysis of Overweight and Obesity in Canadian Adults, the Canadian Community Health Survey (2009).

18. Dinca P S. "Diabetes Prevalence and Income: Result of the Canadian Community Health Survey". London: University Press London (2011).

19. Bloom D. "The Effect of Health on Economic Growth: A Production Function Approach". World Development Ontario: Canada Publishers LTD (2012).

20. Brown J B., et al. "Use of Medical Services and Medicines Attributable to Diabetes in Saharan Africa”. Plos One 9.9 (2014).
21. Creatore MI., et al. "Socioeconomic Status and Diabetes". In: Glazier RH, Booth GL, Toronto: Clinical Evaluative Sciences. Toronto (2007).

22. Nisar., et al. "Association of Diabetic Neuropathy with Duration of Type 2 Diabetes and Glycemic Control". Cureus. Kigali: University of Rwanda 7.8 (2015).

23. Beulens J W., et al. "The Global Burden of Diabetes and Its Complications An Emerging Pandemic". European Journal of Cardiovascular Prevention and Rehabilitation, 17.1 (2018): 5358.

24. Walker R., et al. "Stroke Incidence in Rural Urban Tanzania A Prospective, Community - Based Study". Lancet Neurology 9.8 (2010): 786-792.

\section{Assets from publication with us}

- Prompt Acknowledgement after receiving the article

- Thorough Double blinded peer review

- Rapid Publication

- Issue of Publication Certificate

- High visibility of your Published work

Website: www.actascientific.com/

Submit Article: www.actascientific.com/submission.php

Email us: editor@actascientific.com

Contact us: +919182824667 